\title{
A case of unusual etiology for thrombocytopenia in a young male
}

\author{
Najeebah A. Bade ${ }^{1}$, Min-Ling L. Liu², Dalia A. Mobarek ${ }^{3}$ \\ 1. Department of Internal Medicine, Georgetown University School of Medicine, Hematology Section Washington DC \\ Veterans Affairs Medical Center, Washington DC, USA. 2. Department of Pathology Washington DC Veterans Affairs \\ Medical Center, Washington DC, USA. 3. Hematology Section Washington DC Veterans Affairs Medical Center, Hematology \\ and Medical Oncology Section George Washington University, Hematology and Medical Oncology Section Georgetown \\ University, Washington DC, USA.
}

Correspondence: Dalia A. Mobarek. Address: Hematology Section Washington DC Veterans Affairs Medical Center, Hematology and Medical Oncology Section George Washington University, Hematology and Medical Oncology Section Georgetown University, Washington DC, USA. Email: dalia.mobarek@va.gov

Received: February 2, 2015

DOI : $10.5430 /$ crim.v2n2p85
Accepted: March 9, 2015

URL: http://dx.doi.org/10.5430/crim.v2n2p85

\section{Abstract}

Anorexia nervosa (AN) has a lifetime prevalence in men of $0.2 \%-0.3 \%$. AN has been implicated in hematologic abnormalities including anemia, leukopenia, and less frequently thrombocytopenia. Only about $5 \%$ of patients with AN related cytopenias will have thrombocytopenia.

Herein we discuss a patient with AN who initially presented with fatigue and thrombocytopenia (platelet count nadir of $49,000 / \mu \mathrm{L}$ ). His initial workup was negative; however a bone marrow biopsy revealed profound hypocellularity of ten percent. AN related marrow suppression can occur via gelatinous bone marrow transformation as was the situation with our patient. His peripheral cell counts improved with improvement in his nutritional status. This is one of the few case reports of male anorexia leading to profound hypocellularity of the bone marrow.

\section{Keywords}

Thrombocytopenia, Pancytopenia, Hypocellular bone marrow, Anorexia nervosa

\section{I ntroduction}

Anorexia nervosa (AN) is a psychiatric diagnosis based upon the restriction of energy intake compared to what is needed for the body leading to significantly low body weight (DSM-V) ${ }^{[1]}$. The lifetime prevalence of AN is higher in women $(0.9 \%-2.2 \%)$ than in men $(0.2 \%-0.3 \%)^{[2]}$. Unfortunately, patients with AN suffer from not only psychological dilemmas, but also biochemical, and hematologic problems. Herein, we focus on the hematologic abnormalities. The below cited case, to the best of our knowledge, is one of two reported in the US literature, of a male suffering from AN who presented with thrombocytopenia (later pancytopenia) and was found to have a profoundly hypocellular bone marrow. 


\section{Case presentation}

A 28-year-old male of Italian descent presented after he collapsed at work and was taken to a local emergency room for intravenous fluids and discharged home. His past medical history was significant for anorexia nervosa diagnosed 9 years ago, obsessive-compulsive disorder (OCD), and hypogonadotropic hypogonadism, diagnosed 6 years ago. Following his discharge from the local emergency room, he re-presented a few days later with increasing fatigue. Over the prior three months, he had a worsening in his anorexia and OCD-caloric intake was greatly decreased to less than 800 calories per day, he was running 10+ miles per day, and spending an additional 1.5 hours in the gym. There was a resultant 10-pound weight loss in the past two weeks. He was afebrile and denied recent travel, known exposures to radiation or chemicals. He had not been sexually active or had any sexually transmitted infections. His medications included testosterone IM, vitamin D3, multivitamin, calcium, fish oil, whey protein powder. He used to take creatine and omeprazole. He denied herbal/ supplement use, illicit drugs, or alcohol. He smoked cigarettes intermittently years ago. His twin brother is healthy, but both his father and mother have psychiatric diseases (bipolar disorder and depression). There is no family history of malignancy or hematologic disorders.

Physical examination revealed a cachectic malnourished appearing male (48 kg) with dry mucus membranes, mild conjunctival pallor, no splenomegaly, no lymphadenopathy, and no petechiae. Upon presentation, his WBC count was

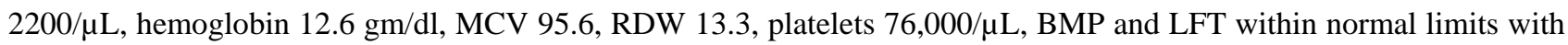
exception of low albumin (2.9 g/dL), iron $20 \mu \mathrm{g} / \mathrm{dl}$, TIBC $246.1 \mu \mathrm{g} / \mathrm{dl}$, ferritin $44.2 \mathrm{ng} / \mathrm{mL}$, B12 > $1500 \mathrm{ng} / \mathrm{mL}$, TSH $2.55 \mu \mathrm{IU} / \mathrm{ml}$, RPR nonreactive, and reticulocyte percent of 1.35\%. The bone marrow biopsy revealed a trilineage $10 \%$ hypocellular bone marrow (see Figure 1). Chromosome analyses was normal (46 XY). A PNH probe was negative. The nadir platelet count was recorded at 49,000/ $\mathrm{L}$ (see Figure 2).

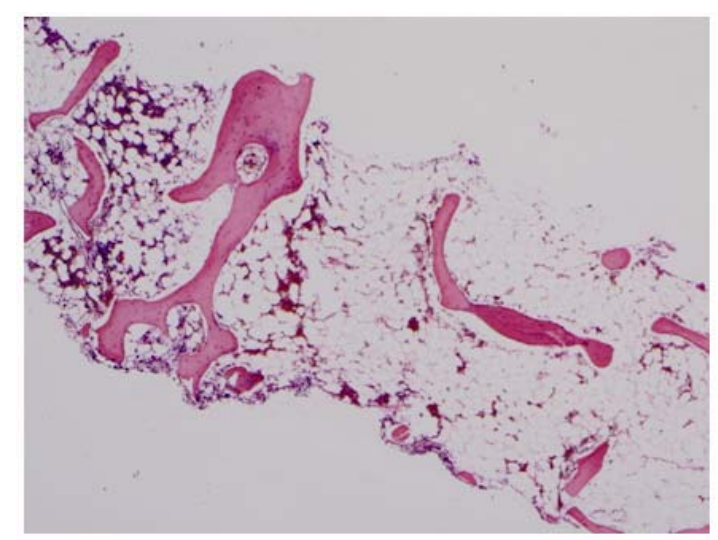

Figure 1. Bone Marrow Biopsy (Bone marrow biopsy showing marked hypocellular marrow for age, ranging from $0 \%-30 \%$ and overall $10 \%$ (Biopsy, H\&E, 40×), consisting of stromal cells with small lymphocytes and plasma cells. In more cellular area, there is trilineage hematopoiesis with maturation in all lines.)

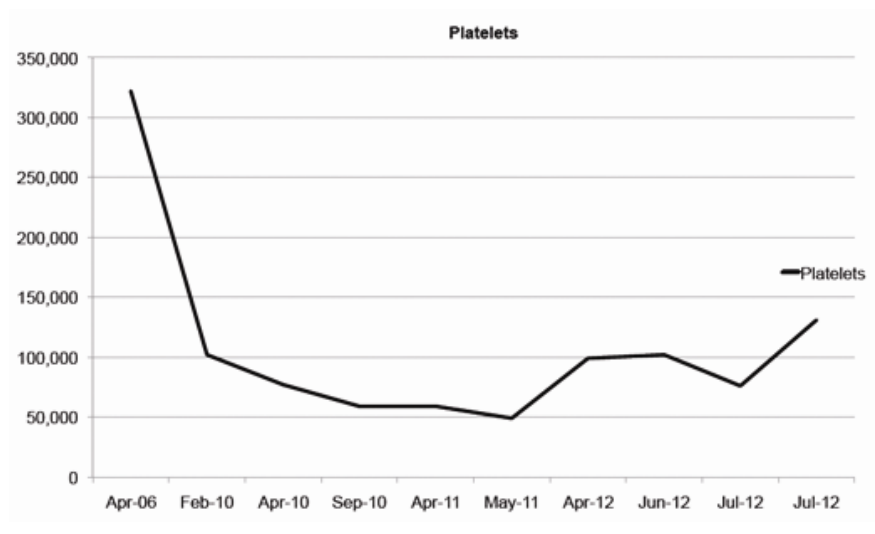

Figure 2. Platelet Count (Platelet count trend from April 2006 through July 2012)

The patient was admitted to the hospital and underwent rigorous psychiatric therapy. Steroid use was not permitted in our patient given his psychiatric condition. After discharge, he continued with cognitive behavioral therapy, his nutritional status improved, and his OCD behaviors decreased. When the patient returned for follow-up with hematology in late July,

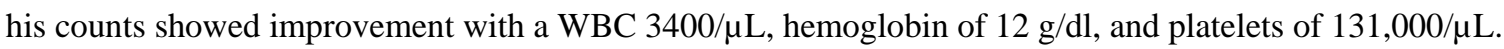




\section{Discussion}

Peripheral blood cytopenias have been shown in AN. In four large retrospective studies, incidence of leukopenia ranged from $22 \%$ to $36 \%$, anemia from $21 \%$ to $39 \%$, and thrombocytopenia from $5 \%$ to $11.3 \%{ }^{[3-8]}$. The cumulative incidence of bipenias or pancytopenia is unclear. Bleeding complications are uncommon in AN associated thrombocytopenia as it is low prevalence and also usually mild in severity. However, one case series discussed 3 female patients with restrictive AN who had life-threatening bleeding in the setting of rapid weight loss immediately prior to admission. Their platelet counts ranged from $23,000-46,000 / \mu \mathrm{L}$ and in two of the patients, correlation was made to hypocellular bone marrow ${ }^{\text {[9] }}$. Our patient had marked weight loss immediately prior to admission, a platelet count of $49,000 / \mu \mathrm{L}$, but did not have any severe bleeding episode. This is much lower than numbers cited in multiple large studies in which platelet counts ranged from $184,000-244,000 / \mu \mathrm{L}^{[4,8,10]}$. Another study cited $90,000 / \mu \mathrm{L}$ as being the lowest number seen in AN associated thrombocytopenia $^{[11]}$.

In young growing mice, caloric restriction was correlated with impaired skeletal acquisition, low leptin, low insulin like growth factor-1 levels, and high marrow adiposity despite lower percent body fat ${ }^{[12]}$. In AN, there is a reduction in normal hematopoietic tissue and increase in fat fraction, size, and number of adipocytes in the bone marrow, but the pathophysiology behind the gelatinous bone marrow transformation is unclear ${ }^{[13]}$. A large retrospective study looked at 80,000 bone marrows and found 155 cases of gelatinous bone marrow transformation (GMT) (fat cell atrophy, focal loss hematopoietic cells, deposition of extracellular gelatinous substances). These cases were usually in adults (twice as likely in men as women), more severe in younger adults, and encompassed a variety of severe generalized illnesses-AN, febrile illnesses, AIDS, and cancer. Seventy-eight percent had weight loss, $81 \%$ had anemia, and thrombocytopenia was not correlated with the GMT. Only $16.8 \%$ of the cited weight loss group had weight loss secondary to malnutrition, which was caused be alcoholism, anorexia, or vegetarian state ${ }^{[14]}$. Chen et al. described a 12-year-old female with AN and complete serous atrophy of her bone marrow but interestingly, no significant peripheral cytopenias ${ }^{[15]}$. Abella et al. reported that often the bone marrow changes are not correlated with peripheral counts ${ }^{[6]}$. Our patient's peripheral cell counts were much higher than would be expected with a $10 \%$ hypocellular marrow with significant serous atrophy.

Marrow adipose tissue was measured in a study and found to be higher in active AN (14 patients) and much lower in recovered AN (15 patients), which was comparable to the healthy control group ${ }^{[16]}$. Another case report described recovery of peripheral counts with adequate nutritional support ${ }^{[17]}$. This reflects that nutritional recovery can lead to bone marrow recovery as is evident from our patient’s clinical course.

In conclusion, AN as a cause of thrombocytopenia in males is unusual. It is important to consider AN as a cause of bone marrow atrophy despite mild cytopenias as it can lead to potentially life threatening consequences.

\section{References}

[1] American Psychiatric Association. 2013. Diagnostic and statistical manual of mental disorders (5th ed.). Washington DC.

[2] Keski R. 2008 American Psychiatric Association: Eating disorders measures. In American Psychiatric Association: Handbook of Psychiatric Measures. Washington, DC: American Psychiatric Association, 2009.

[3] Palla B, Litt IF. Medical complications of eating disorders in adolescents. Pediatrics. 1988; 81: 613-23. PMid:3162764

[4] Devuyst O, Lambert M, Rodhain J, et al. Haematological changes and infectious complications in anorexia nervosa: A case-control study. Q J Med. 1993; 86: 791-9. PMid:8108536

[5] Alvin P, Zogheib J, Rey C, et al. Severe complications and mortality in mental eating disorders in adolescence. On 99 hospitalized patients. Arch Fr Pediatr. 1993; 50: 755-62. PMid:8060204

[6] Abella E, Feliu E, Granada I, et al. Bone marrow changes in anorexia nervosa are correlated with the amount of weight loss and not with other clinical findings. Am J Clin Pathol. 2002; 118: 582-8. http://dx.doi.org/10.1309/2Y7X-YDXK-006B-XLT2

[7] Miller KK, Grinspoon SK, Ciampa J, et al. Medical findings in outpatients with anorexia nervosa. Arch Intern Med. 2005; 165: 561-6. PMid:15767533 http://dx.doi.org/10.1001/archinte.165.5.561 
[8] Misra M, Aggarwal A, Miller KK, et al. Effects of anorexia nervosa on clinical, hematologic, biochemical, and bone density parameters in community-dwelling adolescent girls. Pediatrics. 2004; 114: 1574-83. PMid:15574617 http://dx.doi.org/10.1542/peds.2004-0540

[9] Saito S, Kita K, Morioka CY, et al. Rapid Recovery from Anorexia Nervosa after a Life-threatening Episode with Severe Thrombocytopenia: Report of Three Cases. Int J Eat Disord. 1999, 25: 113-18. http://dx.doi.org/10.1002/(SICI)1098-108X(199901)25:1<113::AID-EAT15>3.0.CO;2-D

[10] Lambert M, Hubert C, Depresseux G, et al. Hematological changes in anorexia nervosa are correlated with total body fat mass depletion. Int J Eat Disord. 1997; 21: 329-34. http://dx.doi.org/10.1002/(SICI)1098-108X(1997)21:4<329::AID-EAT4>3.0.CO;2-Q

[11] Hutter G, Ganepola S, Hofmann WK. The Hematology of Anorexia Nervosa. Int J Eat Disord. 2009; 42: 293-300. PMid:19040272 http://dx.doi.org/10.1002/eat.20610

[12] Devlin M, Cloutier AM, Thomas NA, et al. Caloric Restriction Leads to High Marrow Adiposity and Low Bone Mass in Growing Mice. Journal of Bone and Mineral Research. 2010; 25(9): 2078-88. PMid:20229598 http://dx.doi.org/10.1002/jbmr.82

[13] Cornbleet PJ, Moir RC, Wolf PL. A histochemical study of bone marrow hypoplasia in anorexia nervosa. Virchows Arch A Pathol Anat Histol. 1977; 374: 239-47. PMid:142350 http://dx.doi.org/10.1007/BF00427118

[14] Bohm J. Gelatinous Transformation of the Bone Marrow: The Spectrum of Underlying Diseases. Am Jour of Surgical Pathology. 2000; 24(1): 56-65. PMid:10632488 http://dx.doi.org/10.1097/00000478-200001000-00007

[15] Chen SH, Hung IJ, Jaing TH, et al. Gelatinous Degeneration of the Bone Marrow in Anorexia Nervosa. Chang Gung Med J. 2004; 27: 845-49. PMid:15796262

[16] Fazeli PK, Bredella MA, Freedman L, et al. Marrow fat and preadipocyte factor-1 levels decrease with recovery in women with anorexia nervosa. Accepted article Journal of Bone and Mineral Research. 2012. PMid:22508185 http://dx.doi.org/10.1002/jbmr.1640

[17] Nishio S, Yamada H, Yamada K, et al. Severe Neutropenia with Gelatinous Bone Marrow Transformation in Anorexia Nervosa: A Case Report. Int J Eat Disord. 2003; 22: 360-3. PMid:12655634 http://dx.doi.org/10.1002/eat.10143 